\title{
AUGUSTUS
}

\section{TRILHAS: MOTIVAÇÕES E PERCEPÇÕES DOS PARTICIPANTES DE UM GRUPO DO ESTADO DO RIO DE JANEIRO ${ }^{1}$}

\author{
Ana Carla da Conceição Silva Nunes \\ Graduação em Educação Física Licenciatura pelo Centro Universitário Augusto Motta \\ (UNISUAM), RJ, Brasil \\ carlaconceicao33@hotmail.com
}

Diogo Gonçalves de Souza de Oliveira

Mestrado em Educação Física pela Universidade Federal do Rio de Janeiro (UFRJ), RJ, Brasil

prof.diogo.oliveira@hotmail.com

Giannina Maria do Espirito Santo Wildhagen Doutorado, Mestrado e Graduação em Educação Física pela Universidade Gama Filho (UGF), RJ, Brasil giannina.es@gmail.com

\section{RESUMO}

O objetivo foi verificar os motivos e percepções dos componentes de um grupo de adeptos à prática de trilha no estado do Rio de Janeiro formado a partir de um perfil de uma rede social. Trata-se de uma pesquisa quantitativa e sua análise foi realizada a partir do núcleo central das representações sociais. $O$ estudo contou com praticantes de trilha de ambos os sexos, no entanto mais da metade da amostra é composta por mulheres e com ensino superior completo. Os praticantes estão motivados pela vontade de estar em contato com a natureza. A trilha é representada pela natureza e o condicionamento físico. Já a atividade física ficou associada à saúde e ao condicionamento físico.

Palavras-chave: Atividades de lazer. Motivações. Percepção.

\section{TREKKING: MOTIVATIONS AND PERCEPTIONS OF PARTICIPANTS IN A GROUP FROM THE STATE OF RIO DE JANEIRO}

\begin{abstract}
The objective was to verify the reasons and the perceptions of the members of a group of trekking practitioners in the state of Rio de Janeiro from from a profile of an online social network. It is a quantitative research and its analysis was carried out based on the central nucleus of social representations theory. The study included trekking practitioners of both genders, however more than half of the sample is constituted of women whith higher education. Practitioners are motivated by the desire to be in contact with nature. Trekking is represented by nature and physical conditioning. Physical activity, on the other hand, was associated with health and physical conditioning.
\end{abstract}

\footnotetext{
${ }^{1} \mathrm{O}$ presente trabalho não contou com apoio financeiro de nenhuma natureza para sua realização. Não há conflito de interesses.
} 
TRILHAS: MOTIVAÇÕES E PERCEPÇÕES DOS

PARTICIPANTES DE UM GRUPO DO ESTADO

DO RIO DE JANEIRO
Ana Carla da Conceição Silva Nunes

Diogo Gonçalves de Souza de Oliveira

Giannina Maria do Espirito Santo Wildhagen

Keywords: Leisure activities. Motivations. Perception.

Recebido em: 26/07/2020.

Aceito em: 22/09/2020. 
TRILHAS: MOTIVAÇÕES E PERCEPÇÕES DOS PARTICIPANTES DE UM GRUPO DO ESTADO DO RIO DE JANEIRO
Ana Carla da Conceição Silva Nunes Diogo Gonçalves de Souza de Oliveira Giannina Maria do Espirito Santo Wildhagen

\section{INTRODUÇÃO}

A busca por prazer e sensação de bem-estar acompanha o homem nas diversas fases de sua vida. As manifestações de lazer na sociedade estão atreladas ao tempo, tempo esse que se constrói de acordo com as exigências do dia a dia. Elias (1998, p. 14) aborda a questão apontando que o tempo tem subjetivismos filosóficos, nele se tem o "sentimento de irreversibilidade ligado à experiência que cada um tem do tempo". Esse cenário passa pela situação em que a "determinação do tempo tem funções precisas, as quais, por sua vez, podem modificar-se de maneira específica no decorrer do desenvolvimento da sociedade".

Dumazedier (1999), em uma das definições sobre lazer, aponta que dispor de um tempo, cuja finalidade é a autossatisfação, é uma evolução e uma conquista social. Ele também cita as divisões dos períodos de lazer propostas desde 1960, que são: o lazer do fim do dia (final da jornada de trabalho), do fim da semana (sábados e domingos), do fim do ano (férias) e do fim da vida (aposentadoria). Dumazedier (1999) referia-se a períodos desejados por trabalhadores, momentos considerados favoráveis ao descanso ou à satisfação pessoal, onde qualquer atividade não obrigatória imposta por religião ou família poderia ser realizada. O momento em que a pessoa realiza alguma atividade por prazer, por sentir-se bem, por querer fazer.

O tempo e o tipo de lazer vêm se modificando ao longo dos anos, com as adaptações necessárias. A vida nas grandes cidades, a exemplo do Rio de Janeiro, leva a dificuldades para o tempo de lazer. Muito tempo no trânsito, acúmulo de funções e violência, são questões que emergem a outros olhares para o lazer, que levam a variados tipos de pessoas buscarem uma maior aproximação da natureza, da aventura e do risco.

Alguns estudos demonstraram que a busca pela prática de atividade física de aventura na natureza está relacionada à evasão das grandes metrópoles, melhorias na qualidade de vida, nas sensações de bem-estar e prazer (TAHARA; CORNICELLI FILHO, 2009; CARDOSO; SILVA; FILIPE, 2006).

Spink, Aragaki e Alves (2005, p. 29) definiram aventura como "a busca de desafios relacionados com a imponderabilidade e imprevisibilidade". Já o risco como "a probabilidade de ocorrência de um evento indesejável, como acidentes ou, no caso extremo, a morte". Lavoura, Schwartz e Machado (2008) observaram que a prática de atividade física de aventura 
na natureza com jovens, que fizeram pela primeira vez a atividade de rapel no âmbito da natureza, apresentava sentimentos de receio e de prazer.

Dentre as diversas formas de lazer, os esportes não convencionais vêm ganhando espaço entre a população de mais idade. Este fato foi destacado por Luiz e Teixeira (2016), ao realizarem um estudo sobre acessibilidade, conservação e democratização de espaços públicos. Os autores verificaram que, frente ao processo de urbanização, a busca por atividades de lazer em áreas naturais é cada vez mais crescente.

Pessoas de diferentes faixas etárias, formação cultural, níveis sociais e de atuação em diversas áreas e profissões, estão se interessando mais por atividades que lhes proporcionem a sensação de aventura, adrenalina, risco, fortes emoções e superação, que Ihes concedam belas paisagens e as façam se sentir mais próximas à natureza, e esse é um dos motivos que inspiram as pessoas (PAIXÃO et al., 2011).

Schwartz et al. (2016) observaram que um dos motivos para essa adesão é poder ter o contato com o ambiente natural. Este fato tem sido um grande motivador para qualificar a relação ser humano-natureza. Eles puderam verificar que a satisfação, a superação, o prazer, as vivências de sensações e emoções que a prática de atividades como trilhas proporcionam são fatores que contribuem para o crescente interesse de pessoas não atletas por esta prática, vista por alguns como algo arriscado.

Moreira e Schwartz (2010) investigaram sete indivíduos, de ambos os sexos, em um trajeto conhecido como "Caminhada da Fé", que são 425 km entre duas cidades do estado de São Paulo e que atrai diversas pessoas dentre elas praticantes de atividades físicas de aventura na natureza. O estudo apresenta alguns resultados interessantes: antes da caminhada os pesquisados notaram diferenças entre o ambiente da cidade (destruído) e o rural (preservado); durante a caminhada e ao final da caminhada, nestes dois momentos, o desmatamento foi destacado. Os autores concluíram que a partir desses três momentos distintos puderam contribuir, mesmo que indiretamente, para possíveis reflexões e mudanças positivas de atitude, de seus participantes, em relação ao meio ambiente.

Em um estudo realizado com 15 praticantes de kitesurf na região Nordeste do Brasil foi encontrado que os mesmos apresentam percepções e motivações favoráveis entre a prática da atividade física de aventura na natureza com a preservação do meio ambiente, além de agregar benefícios aos praticantes, como uma maior sensibilidade ao meio ambiente e 
melhora nas questões socioeconômicas do locus da prática e nas relações psicoemocionais (LUCENA; SILVA; BRASILEIRO, 2013).

Paixão et al. (2011) analisaram o risco na percepção de instrutores, pessoas, quase sempre homens, que trabalham em grande maioria na informalidade e acompanham os novos e veteranos adeptos a esportes e atividades deste tipo, considerado por muitos como esporte de aventura. Apesar de não ser reconhecido oficialmente como profissão, salvo por algumas instituições esportivas, o instrutor é uma figura importante neste tipo de atividade. É a pessoa que deve conhecer o local da trilha, saber onde ficam os melhores acessos, os que são vistos como mais fáceis ou de nível iniciante a intermediário e os mais difíceis, considerados como de nível avançado. Também a responsabilidade de avaliar por qual caminho o grupo que o segue tem condição de ir e, assim, conduzir todos na maior segurança possível.

Os referidos autores chegaram à conclusão que, para vivenciar de forma plena as sensações proporcionadas pela atividade de trilha, os adeptos precisam ter consciência de que o perigo é permanente e que, em algum momento, a técnica e a coragem não são suficientes para impedir um imprevisto. É indispensável ter além de vontade e disposição, atenção, prudência e respeito aos indícios da natureza, para que tudo corra de maneira favorável ao divertimento e lazer, sem pôr em risco a integridade física e saúde dos participantes (PAIXÃO et al. 2011).

Este estudo tem por objetivo verificar os motivos e percepções dos componentes de um grupo de adeptos à prática de trilhas, moradores do estado do Rio de Janeiro, que se formou a partir de um perfil de uma rede social.

\section{METODOLOGIA}

Trata-se de uma pesquisa transversal observacional, do tipo quantitativo, que utilizou como instrumento um questionário fechado, produzido especialmente para este estudo.

O questionário tem em suas questões iniciais a técnica de associação livre de ideias, que é utilizada para determinação do Núcleo Central das Representações Sociais, tendo os termos indutores "atividade física" e "trilha". No segundo momento são realizadas diversas questões fechadas sobre os motivos da prática da trilha, em relação ao tempo de prática (da trilha e de alguma atividade física), se realiza algum esporte e/ou exercício físico e, por fim, as percepções dessa prática da trilha. Essa forma de abordagem se desenvolve porque "a própria 
TRILHAS: MOTIVAÇÕES E PERCEPÇÕES DOS PARTICIPANTES DE UM GRUPO DO ESTADO DO RIO DE JANEIRO
Ana Carla da Conceição Silva Nunes Diogo Gonçalves de Souza de Oliveira Giannina Maria do Espirito Santo Wildhagen

noção de indivíduo passa a ser socializada, sendo este visto como um "ser da interação" (SPINK, 2003, p. 73). Desta forma as estratégias adotadas "buscam desconstruir a dicotomia entre os estados individuais e comportamentais, passando a entender todas as manifestações das subjetividades como práticas sociais" (SPINK, 2003, p. 73).

A população pesquisada e escolhida por conveniência faz parte de um grupo constituído através de uma rede social para o incentivo da prática da atividade física no tempo de lazer, que era composto por 364 participantes até o dia sete de agosto de 2016, quando este estudo foi elaborado, de origem diversas, tendo pessoas de diferentes extratos sociais e localidades do estado do Rio de Janeiro, sendo que a faixa etária de 35 a 44 anos correspondia a 50 pessoas. Através do contato nas redes sociais, marcam atividades a serem realizadas, principalmente, trilhas. Esse grupo foi constituído através da busca de atividades na natureza partilhada com outras pessoas. Uma das autoras do artigo foi agregando em seu Facebook as pessoas que tinham esse desejo. Periodicamente parte do grupo se encontrava para realização de trilhas e outras atividades na natureza. Muitos apenas pegavam dicas para a realização de atividades de acordo com suas disponibilidades.

Exatamente por ser a de maior participação, essa faixa etária foi selecionada para o estudo. Para o cálculo do tamanho amostral foi utilizado um erro estipulado em 7\%, para um nível de confiança de $90 \%$ e prevalência presumida de $50 \%$ para os motivos e percepções dos integrantes do grupo em questão. Sendo assim, o tamanho da amostra foi de 37.

Em cumprimento à Resolução 510/16 da CONEP, todos os participantes da pesquisa foram informados sobre os riscos e benefícios do estudo e, em concordância, assinaram o termo de consentimento livre e esclarecido (TCLE). Cabe ressaltar que o estudo foi aprovado pelo Comitê de Ética em Pesquisa do Centro Universitário Augusto Motta sob o CAAE: 59892916.0 .0000 .5235 .

A coleta de dados foi realizada através do grupo da rede social, utilizando o chat individual para serem passados o TCLE e o questionário. Desta forma, favoreceu a menor disponibilização de tempo do participante. Foram enviados convites a todos os componentes do grupo que estivessem dentro do critério de inclusão, para além do número de pessoas desejadas, para favorecer ao maior número de participantes. Aqueles que responderam positivamente ao TCLE, receberam em seguida o questionário do estudo. 
TRILHAS: MOTIVAÇÕES E PERCEPÇÕES DOS PARTICIPANTES DE UM GRUPO DO ESTADO DO RIO DE JANEIRO
Ana Carla da Conceição Silva Nunes Diogo Gonçalves de Souza de Oliveira Giannina Maria do Espirito Santo Wildhagen

\subsection{Análise de dados}

O núcleo central das representações sociais foi calculado através da relação da ocorrência das palavras associadas às indutoras, considerando sua frequência e a ordem de evocação. Sendo assim, partiu-se de que as palavras que se apresentassem, ao mesmo tempo, aos critérios de evocação com maior frequência e às citadas em primeiros lugares, teriam uma maior importância no cognitivo do sujeito, por isso designariam o núcleo central (SÁ, 2002). Ele se torna o principal elemento da representação que foi formada por um dado grupo investigado, favorecendo a superação "do simples quadro do objeto das representações para encontrar sua origem diretamente nos valores que os transcendem" (ESPÍRITO-SANTO; MOURÃO, 2012, p. 39). Por isso, é mais estável das representações, permitindo a perenidade onde o contexto pode ser móvel. Se estabelece em parte pela relação que o sujeito ou grupo possui com o objeto (SÁ, 2002).

Já as palavras citadas, ainda que com alta frequência, mas de maneira mais tardia, e aquelas de baixa frequência e citadas rapidamente seriam consideradas pertencentes ao sistema intermediário. Estas teriam alguma influência para a formação do esquema cognitivo, mas de menor relevância (SÁ, 2002).

Aquelas de baixa frequência e tardia evocação estariam localizadas no sistema periférico, que tem características de facilidade de alteração de seu contexto, pela sua pouca expressão no esquema cognitivo (SÁ, 2002).

O esquema de análise dos dados é representado por meio do quadro das quatro casas, relacionando a frequência e a ordem média de evocação, que é o quociente entre ponderação das evocações e o somatório delas.

No segundo momento os dados foram analisados através da estatística descritiva, utilizando a média, o número de ocorrência e o percentual.

\section{APRESENTAÇÃO E DISCUSSÃO DOS RESULTADOS}

Os resultados foram apresentados a partir da divisão em temas provenientes das perguntas realizadas no questionário. 
TRILHAS: MOTIVAÇÕES E PERCEPÇÕES DOS

PARTICIPANTES DE UM GRUPO DO ESTADO

DO RIO DE JANEIRO
Ana Carla da Conceição Silva Nunes

Diogo Gonçalves de Souza de Oliveira Giannina Maria do Espirito Santo Wildhagen

\subsection{Características da amostra}

O grupo analisado foi formado em 5 de abril de 2015, inicialmente com 20 participantes que se comunicavam por meio de um aplicativo de celular, onde marcavam passeios e trilhas. Em um período de um ano, o grupo já tinha alcançado a marca dos 360 participantes e durante a construção deste estudo, alcançou o número de 408 membros. O aumento do número de participantes em tão pouco tempo mostra que está crescendo o interesse em participar de grupos que organizam e ou facilitam o acesso à prática de atividades ao ar livre, visto que a grande maioria dos entrevistados aderiu recentemente. Devido ao número de pessoas que se uniram ao grupo, a comunicação precisou ser expandida e hoje as redes sociais também fazem parte do meio de comunicação utilizado para marcar eventos e encontros.

Dentro da faixa etária escolhida para a pesquisa, a maioria das pessoas que respondeu ao questionário foi do sexo feminino com idade de 37 a 39 anos, cuja escolaridade apresentada com maior prevalência foi de ensino superior completo (Tabela 1). Com este resultado, pode-se dizer que mulheres adultas e graduadas estão, de forma crescente, se inserindo a este tipo de esporte. Diferentemente do referido achado, Dall'oglio, Sheng e Benitez (2017), ao verificarem o perfil dos visitantes de um parque em Mato Grosso do Sul entre os meses de fevereiro e março de 2014 , evidenciaram que $65,06 \%$ dos frequentadores são jovens com idades entre 14 e 18 anos, estudantes do ensino médio (cursando e/ou concluintes), solteiros e sem filhos. Gomes e Isayama (2009) encontraram em praticantes de práticas esportivas e de lazer de aventura são em sua maioria homens e com idades entre 21 e 30 anos.

A maior participação das mulheres pode ter sido incentivada pelo fato de a organizadora do grupo ser do sexo feminino. Schwartz et al. (2016) verificaram que as mulheres se inserem em atividades de aventura, pelo gosto e pela identificação com esportes que propiciam o contato com a natureza. $\mathrm{O}$ estabelecimento de redes sociais para divulgação de anseios, motivações, conquistas e superações é algo que atrai números cada vez mais expressivos de participantes mulheres. 
Tabela 1 - Características dos sujeitos.

\begin{tabular}{lc}
\hline Sexo & $\mathbf{n}$ \\
\hline Masculino & 16 \\
Feminino & 21 \\
\hline Faixa Etária (em anos) & \\
\hline 34 a 36 & 10 \\
37 a 39 & 18 \\
40 a 42 & 5 \\
43 a 45 & 4 \\
\hline Escolaridade & \\
\hline Fundamental completo & 3 \\
Fundamental incompleto & 4 \\
Ensino Médio completo & 6 \\
Ensino Médio incompleto & 2 \\
Superior completo & 17 \\
Superior incompleto & 3 \\
Não informado & 2 \\
\hline
\end{tabular}

Fonte: Autor (2020).

\subsection{Significados de trilha}

De acordo com o Quadro 1, estar em contato com a natureza em conjunto com a melhora do condicionamento físico tem a maior representação ou significado de se fazer uma trilha ficaram no Núcleo Central das Representações Sociais do grupo pesquisado. O Rio de Janeiro é uma cidade que possui muitas ofertas de passeios e trilhas, em parques e praias, que favorecem a esse contato com a natureza. O município do Rio de Janeiro torna-se um local privilegiado neste aspecto, pois é coberto por mais de 35 mil hectares de Mata Atlântica, sendo as zonas Oeste e Sul da cidade do Rio de Janeiro as de maior concentração de floresta e tendo quase 50 trilhas espalhadas por toda a cidade (SECRETARIA MUNICIPAL DE MEIO AMBIENTE, 2020). Figueiredo e Schwartz (2013, p. 468) evidenciaram a necessidade da fuga das grandes cidades, toda vez que os praticantes de trilhas têm disponibilidade, buscando esse contato com a natureza. "Sendo assim, a aventura, atrelada aos aspectos de sensações e emoções, liberdade e oportunidade de desafios, pode proporcionar vivências significativas aos indivíduos durante os momentos destinados ao lazer".

O condicionamento físico pode ter surgido sobre dois aspectos. O primeiro pela necessidade dos praticantes se sentirem mais dispostos para o seu dia a dia e, associado a isso, ao lazer de aventura, que de acordo com Spink, Aragaki e Alves $(2005$, p. 27) também se 
TRILHAS: MOTIVAÇÕES E PERCEPÇÕES DOS PARTICIPANTES DE UM GRUPO DO ESTADO DO RIO DE JANEIRO
Ana Carla da Conceição Silva Nunes Diogo Gonçalves de Souza de Oliveira Giannina Maria do Espirito Santo Wildhagen

tornou uma atividade de turismo de aventura. Os autores ainda apontam para a utilização dos esportes de aventura na forma institucional, como por exemplo, "as modalidades de aprendizagem de flexibilidade e decisão nos programas de treinamento e desenvolvimento, desenhados como recurso de treinamento alternativo e que combinam a emoção do esporte na natureza com o treinamento corporativo tradicional". Desse modo, o condicionamento físico também pode ser atribuído a uma questão mais funcionalista. Entretanto, o grupo em questão não se utiliza da atividade, de maneira direta, para o fim de treinamento institucional.

Szeremeta e Zannin (2013) realizaram uma revisão não sistemática em alguns bancos de dados, sites de periódicos, materiais impressos e digitais disponibilizados em uma universidade federal, com intuito de saberem a importância de parques e áreas verdes em espaços urbanos na qualidade de vida e promoção da saúde da população. A revisão conclui que há melhora na qualidade de vida para quem frequenta os parques públicos e as áreas verdes, além de contribuírem para benefícios psicológicos, físicos e sociais e a possibilidade de vislumbrarem uma bela paisagem.

Em outras modalidades realizadas na natureza, tais como enduro a pé, moutain bike e voo livre, percebe-se que os sujeitos relacionam a sua prática em busca de lazer e estilo de vida, por isso a adesão a essas práticas é bem diversificada e caracterizada por um não treinamento prévio. Os autores concluem que as atividades físicas de aventura na natureza "estão mais próximas ao hedonismo turístico do que em comparação aos esportes tradicionais urbanos" (PEREIRA; PIMENTEL; LARA, 2004, p. 118).

A aventura e a curiosidade surgem no sistema intermediário das Representações Sociais, significando que, para esse grupo, tem possibilidades de se tornar central. A curiosidade estabelece relação com aventura, pois o novo tem componentes de imponderabilidade e imprevisibilidade, como destacado por Spink, Aragaki e Alves (2005).

Quadro 1 - Significados de trilha.

\begin{tabular}{|c|c|c|c|c|c|}
\hline ENUCIAÇÕES & $1 \underline{a}$ & $2 \underline{a}$ & 3a & FREQUÊNCIA & OME \\
\hline Natureza & 21 & 12 & 11 & 44 & 1,77 \\
\hline Aventura & 5 & 9 & 6 & 20 & 2,05 \\
\hline Diversão & 4 & 1 & 6 & 11 & 2,18 \\
\hline Condicionamento físico & 5 & 11 & 1 & 17 & 1,76 \\
\hline Bem estar & 2 & 2 & 8 & 12 & 2,50 \\
\hline Animal & 1 & 3 & 3 & 7 & 2,29 \\
\hline Curiosidade & 1 & 0 & 0 & 1 & 1,00 \\
\hline \multicolumn{4}{|c|}{ Média } & 16,00 & 1,94 \\
\hline
\end{tabular}




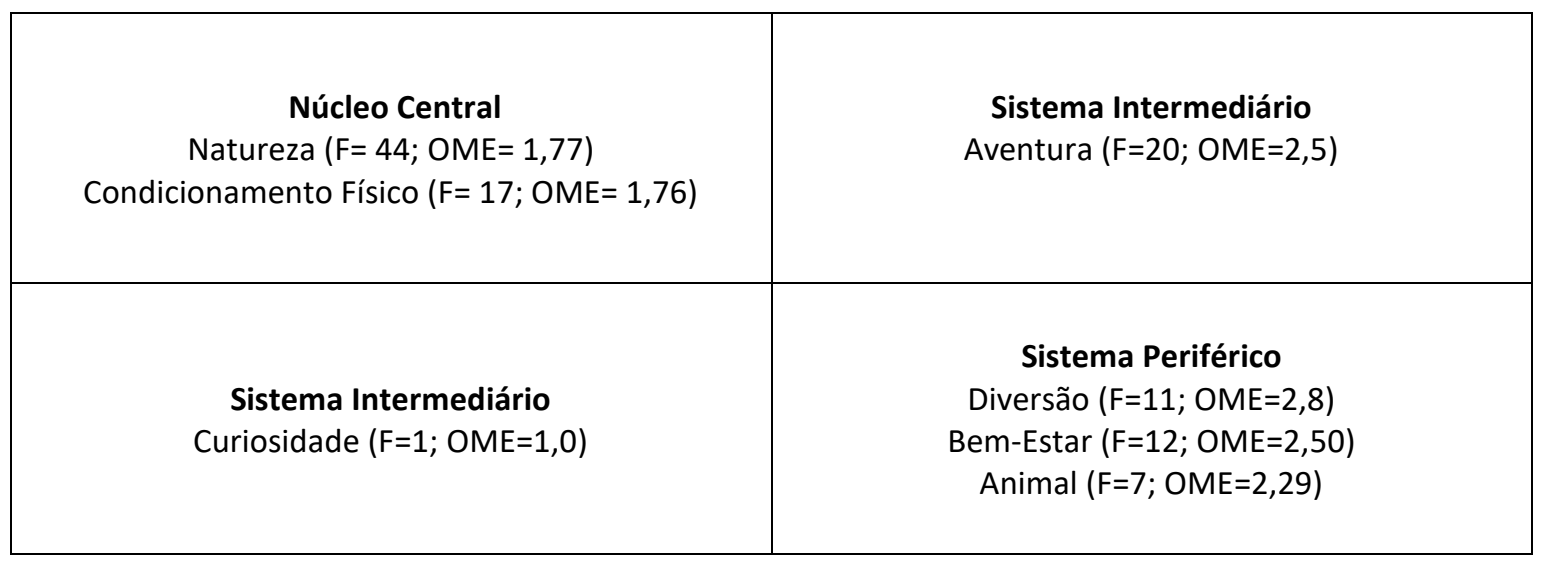

Legenda: Frequência (F); Ordem Média de Evocação (OME).

\subsection{Significados de atividade física}

Fonte: Autor (2020).

De acordo com o Quadro 2, a saúde e o movimento surgem com centralidade para os significados atribuídos para a atividade física. Esse fato parece estar associado ao senso comum estabelecido por alguns estudos, como o de Matsudo (2009) que afirma que a atividade física regular tem um papel fundamental na prevenção e controle das doenças crônicas não transmissíveis, melhora da mobilidade, capacidade funcional e qualidade de vida durante o processo natural de envelhecimento, além de favorecer a realização de atividades de menor a maior complexidade. Essa é uma abordagem recorrente na Educação Física para fortalecer o estatuto epistemológico da área e que está hegemônico no senso comum. Sabemos que as atividades físicas podem contribuir para a saúde, mas não pode ser estabelecida uma relação de causa e efeito. Palma (2001, p. 23) já trazia esse debate, quando atribuía a necessidade de outros modos de olhar para a relação atividade física e saúde. 0 autor destaca que há:

a) a redução do fenômeno a uma determinação biológica; b) a desconsideração da história coletiva; e, c) a culpabilização do indivíduo frente aos problemas de saúde e aptidão física. Por fim, propõe-se que a relação educação física-saúde seja abordada através de novos "olhares", atentos às incertezas e complexidades do processo (PALMA, 2001, p. 23).

Nos sistemas intermediários é possível verificar significados como o condicionamento físico, autoestima e beleza. Este cenário pode ocorrer pela influência da mídia, em que é amplamente divulgada a relação da atividade física na busca de um padrão corporal "ideal". Bastos (2008 apud FERRARI et al., 2012) debate a existência de uma padronização de beleza 
TRILHAS: MOTIVAÇÕES E PERCEPÇÕES DOS PARTICIPANTES DE UM GRUPO DO ESTADO DO RIO DE JANEIRO
Ana Carla da Conceição Silva Nunes Diogo Gonçalves de Souza de Oliveira Giannina Maria do Espirito Santo Wildhagen

corporal feminina amplamente divulgada na mídia, principalmente, na internet, que geram um consumo de informações na busca de meios para alcançar esse padrão corporal.

Antunes, Silva e Baptista (2013, p. 176), ao realizarem um estudo sobre corpo nos programas de pós-graduação, nos quais analisaram duas teses e dezessete dissertações sobre corpo na meia-idade, puderam constatar que as "concepções de corpo e saúde caracterizamse predominantemente por uma perspectiva reducionista e fragmentada, expressa pela exclusividade de análise anátomo-fisiológica e uma ênfase na doença e não na saúde". Este fato reforça o argumento de Palma (2001) e os achados deste estudo.

Baptista e Zanolla (2016) apontaram, a partir da análise de Adorno sobre beleza natural, que se torna necessário:

Refletir sobre a lógica do corpo estandardizado é considerar a ideia de domínio da natureza enquanto caráter repressivo ao processo de elaboração da consciência. É compreender que o corpo modificado atende certa racionalidade voltada para a estética da mercadoria em meio às diferentes relações sociais, sejam elas no trabalho ou em outros espaços em que comparece mais efetivamente o mundo afetivo e sexual (BAPTISTA; ZANOLLA, 2016, p. 1008).

Por outro lado, os participantes da pesquisa podem ter atribuído a beleza da natureza, pelo próprio contato que a prática de trilhas proporciona. Maffesoli (1996, p. 274) relatou que por ser de um mundo que é partilhado com outros, as emoções e os afetos proporcionam sentido e "força à expressão ética da estética"

Vaz et al. (2017) confirmam que é notável o aumento da procura pela vivência de momentos agradáveis junto à natureza. A sensação de paz e privilégio em admirar, apreciar e curtir algo que não exigiu do homem nenhum esforço para existir, contribuem em algumas pessoas para melhorar o convívio social.

Quadro 2 - Significados de atividade física.

\begin{tabular}{|l|c|c|c|c|c|}
\hline ENUCIAÇõES & 1a & 2a & 3a & FREQUÊNCIA & OME \\
\hline Movimento & 6 & 7 & 8 & $\mathbf{2 1}$ & $\mathbf{2 , 1 0}$ \\
\hline Condicionamento Físico & 4 & 3 & 2 & $\mathbf{9}$ & $\mathbf{1 , 7 8}$ \\
\hline Beleza & 2 & 6 & 8 & $\mathbf{1 6}$ & $\mathbf{1 , 8 1}$ \\
\hline Saúde & 25 & 14 & 15 & $\mathbf{5 4}$ & $\mathbf{2 , 0 0}$ \\
\hline Autoestima & 0 & 1 & 0 & $\mathbf{1}$ & $\mathbf{2 , 3 3}$ \\
\hline Desempenho & 0 & 2 & 1 & $\mathbf{3}$ & \\
\hline
\end{tabular}




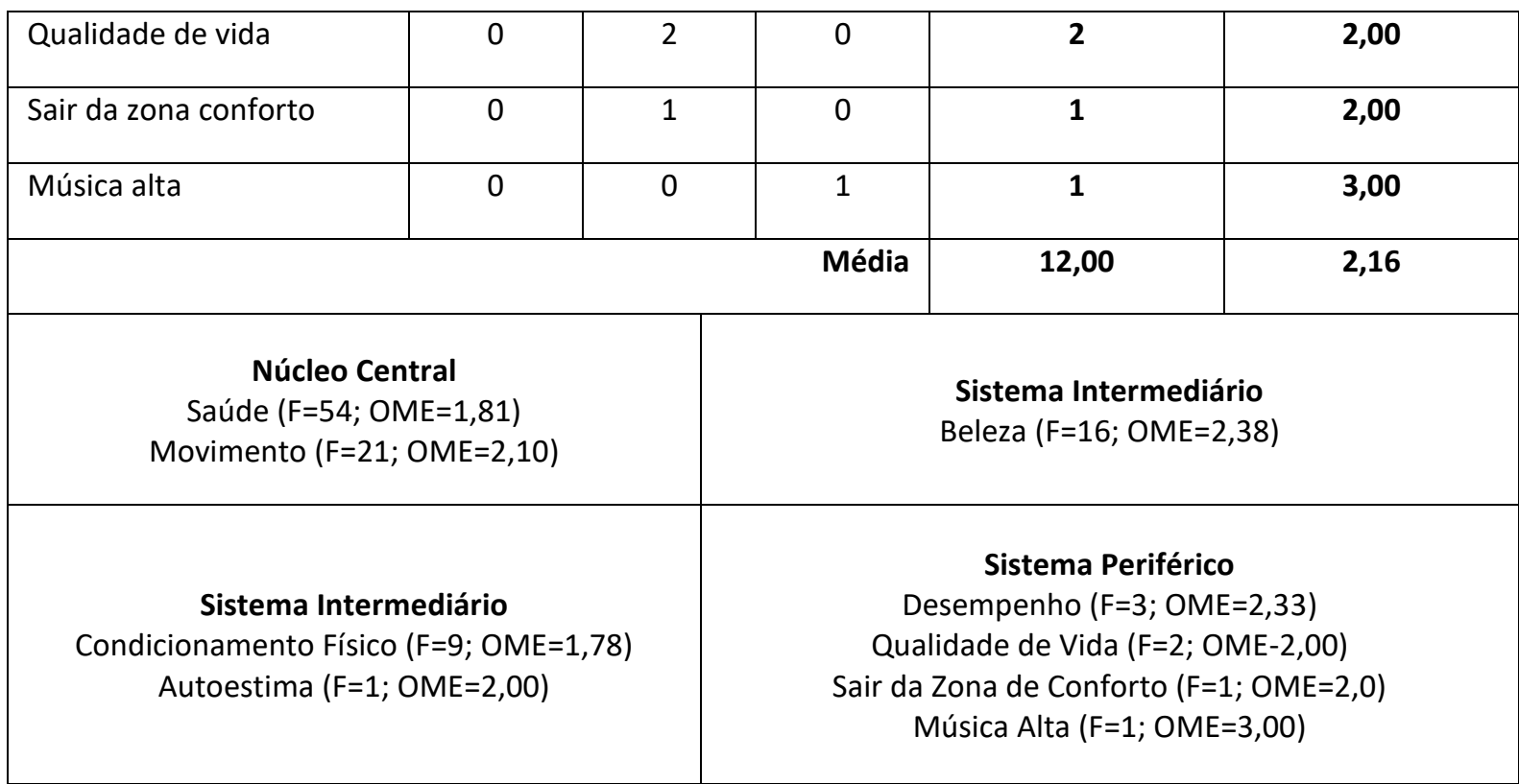

Legenda: Frequência (F); Ordem Média de Evocação (OME).

Fonte: Autor (2020).

\subsection{Sobre prática}

Ao relacionar as respostas à pergunta sobre o tempo de prática de qualquer atividade física e a prática de trilha, podemos observar na Tabela 2 que a prática de trilha é algo relativamente novo para a maioria dos entrevistados (cerca de seis meses de adesão ao esporte), corroborando com a citação de Moura e Soares (2014) de que a visibilidade sobre os esportes de aventura é algo atual. Porém Marinho (2008) aponta que tais esportes não são recentes, mas os significados atribuídos e suas consequências são contemporâneos, principalmente, quando realizados na natureza. Tahara e Carnicelli Filho (2009) investigaram 40 indivíduos sobre os fatores de adesão para as práticas de atividades físicas de aventura na natureza (AFAN) e de exercícios em academias, ambas realizadas no âmbito do lazer, revelando que para as AFAN há uma variação entre um e dez anos de prática em seus participantes, sendo que a maioria (40\%) realiza entre há um e dois anos e, para os exercícios em academias, encontraram $45 \%$ entre quatro e seis anos de prática.

Fazer trilha, propondo-se a caminhar por terrenos irregulares com a presença de pedras e algumas vezes precipícios, pode ser, apesar dos riscos, muito prazeroso e revitalizante, na qual a incerteza, a "imprevisibilidade", os impulsos lúdicos, caracterizados fundamentalmente pela busca por prazeres e pelo seu caráter desinteressado, manifestamse pelo desejo de aventura. Para Paixão et al. (2011), o alívio no barulho ao qual estamos 
TRILHAS: MOTIVAÇÕES E PERCEPÇÕES DOS PARTICIPANTES DE UM GRUPO DO ESTADO DO RIO DE JANEIRO
Ana Carla da Conceição Silva Nunes Diogo Gonçalves de Souza de Oliveira Giannina Maria do Espirito Santo Wildhagen

expostos todos os dias nas grandes metrópoles é algo aguardado por algumas das pessoas investigadas.

Com o crescimento das práticas de esportes na natureza, cresce também o mercado para instrutores. Vaz et al. (2017) realizaram um estudo com 22 indivíduos de ambos os sexos para analisar as percepções e competência dos profissionais que atuam nesse segmento e evidenciaram que existem possíveis lacunas que podem colocar em risco os praticantes, reforçando as observações empíricas e de produções científicas realizadas por Paixão et al. (2011), nas quais abordaram o esporte de aventura, verificando a inexistência, no Brasil, de formação oficial específica para as pessoas que trabalham nessa área. Apesar de o esporte de aventura ser uma realidade em termos de prática física no cenário brasileiro, seja no âmbito do lazer ou da competição:

\footnotetext{
A categoria na qual se insere o instrutor do esporte de aventura no Brasil não dispõe ainda de um status suficientemente capaz de propor uma sistematização das ações, estratégias e procedimentos adotados por esses atores à luz da Pedagogia (nos domínios da didática). Esse status configurar-se-ia numa espécie de referência para a organização e o desenvolvimento do trabalho docente, dadas as novas necessidades sociais da contemporaneidade observadas na vertente do esporte de aventura. (PAIXÃO et al., 2011, p. 419).
}

Ao analisarem os riscos percebidos, Moura e Soares (2014) observaram que o campo do turismo tem privilegiado apenas o ponto de vista dos iniciantes. Dessa forma, sugerem que a área do esporte, ao analisar os riscos, investigue todos os níveis de participação nessas modalidades, porque o fato de ter certa vivência ou até mesmo de "conhecer" bem o trajeto a ser percorrido não isenta o indivíduo dos riscos aos quais está exposto, tendo em vista que o ambiente natural muda constantemente devido à ação da chuva, do vento, da intervenção animal e humana. A autoconfiança exagerada faz com que o indivíduo relaxe com cuidados básicos necessários para a permanência, mesmo que curta, em um espaço natural. Com isso, nota-se que os instrutores não devem esquecer de prestar atenção nos participantes com mais experiência tanto quanto aos novos adeptos. 
Tabela 2 - Sobre as práticas.

\begin{tabular}{lcc}
\hline \multicolumn{1}{r}{ Tempo } & Trilha & Atividade Física \\
\hline Menos de 1 ano & 15 & 6 \\
1 ano & 8 & 4 \\
1 ano e 6 meses & 5 & 1 \\
2 anos & 2 & 14 \\
Mais de 2 anos & 6 & 11 \\
\hline
\end{tabular}

Fonte: Autor (2020).

\subsection{Melhoras com a participação no grupo de realização de trilhas}

Belas paisagens esculpidas pela natureza encontradas nas trilhas podem ser citadas como um grande fator motivador para que as pessoas encontrem disposição e vontade de caminhar e se aventurar neste tipo de atividade. Todos que responderam as questões relataram perceber alguma mudança em suas vidas, tais como: melhoras no relacionamento com outras pessoas $(n=10)$, humor $(n=9)$, força muscular $(n=11)$, ânimo $(n=18)$, felicidade $(n=11)$ e até disposição no dia a dia $(n=11)$ para realização de suas atividades (Tabela 3$)$. Cardoso, Marinho e Pimentel (2013) constataram que indivíduos que se exercitam têm maiores chances de serem mais satisfeitos e felizes com seus corpos e, por consequência, terem uma melhor autoestima favorecida por uma melhor imagem corporal que indivíduos sedentários. Cabe ressaltar que a determinação de sedentarismo possui incongruências quando aplicadas diferentes metodologias utilizadas nos estudos epidemiológicos. Este fato foi evidenciado por Palma e Vilaça (2010), quando realizaram um ensaio relacionando estudos epidemiológicos com diferentes medidas de sedentarismo.

Tahara e Conicelli Filho (2009) verificaram que houve alterações estéticas e fisiológicas nos praticantes de esportes na natureza, destacando também as mudanças psicológicas, tais como: melhoras na satisfação pessoal e bem-estar e no sentimento de liberdade em superação de desafios, além de aumento da autoestima. Resultados semelhantes também foram encontrados por Lavoura, Schwartz, Machado (2008), ao realizarem um estudo com oito jovens de ambos os sexos, com 28 anos de idade em média e com ensino superior completo, que experimentaram pela primeira vez a modalidade de rapel como uma atividade de aventura na natureza. O estudo infere que há possibilidades de valorização intra e interpessoais, uma maior reaproximação entre homem e natureza, maior 
reflexão sobre os valores da vida no seu dia a dia, além de possibilitar misturas de diferentes emoções, sentimentos e sensações.

Percebe-se que com a correria das grandes metrópoles e o estresse que este quadro pode proporcionar, a adesão às trilhas se apresenta, particularmente para o grupo investigado, como uma estratégia de resistirem a essas condições adversas do dia a dia. Com isso, nota-se de forma despretensiosa que o homem, enquanto ser existente no planeta, tende a recorrer à natureza para suprir suas necessidades. Esse quadro foi verificado por Armas e Inácio (2010, p. 25) quando realizaram estudo com montanhistas e puderam observar que a atividade era capaz de ajudar com os desgastes produzidos pelo trabalho, visto que o prazer da prática promoveu possibilidades para restaurar as energias para "enfrentar as agruras cotidianas do mundo do trabalho". É preciso ressaltar que a atividade não deve ser vista como ferramenta da reprodução da exploração do trabalhador, pois quando se desenvolvem atividades que objetivem apenas o melhor desempenho e que deixem de propiciar formas de resistências ao capital, favorecem a alienação do sujeito ao quadro de afastamento do Estado, o neoliberalismo. Lupton (2003, p. 14) destaca que:

O neoliberalismo reitera princípios liberais clássicos, tais como a ideia de que cidadãos são atores racionais, autônomos e que o Estado deve evitar a intervenção excessiva nos assuntos privados e no bem-estar dos cidadãos. Sob a égide neoliberal, somos encorajados a nos tornar "sujeitos de nós mesmos", a exercermos um tipo de liberdade regulada como parte do funcionamento do poder político. Isso inclui desenvolver atividades de autorreflexão e auto aperfeiçoamento, que convergem com os objetivos governamentais, como parte dos nossos esforços para atingir sucesso e felicidade individuais. A noção contemporânea de cidadania define esse movimento como "ativo e individualista em vez de passivo e dependente" (LUPTON, 2003, p. 14).

Tabela 3 - Percepções da prática.

\begin{tabular}{lc}
\hline Percepções da prática & $\mathbf{n}$ \\
\hline Ânimo & 18 \\
Autoestima & 8 \\
Estresse & 9 \\
Felicidade & 11 \\
Humor & 9 \\
Relacionamento & 10 \\
Alimentação & 2 \\
Disposição no dia a dia & 11 \\
Dor no corpo & 2 \\
Memória & 5 \\
Sono & 5 \\
Controle da Pressão Arterial & 5
\end{tabular}


TRILHAS: MOTIVAÇÕES E PERCEPÇÕES DOS PARTICIPANTES DE UM GRUPO DO ESTADO DO RIO DE JANEIRO
Ana Carla da Conceição Silva Nunes Diogo Gonçalves de Souza de Oliveira Giannina Maria do Espirito Santo Wildhagen

\begin{tabular}{lc} 
Força muscular & 11 \\
Flexibilidade & 5 \\
Triglicerídeos & 5 \\
Obesidade & 5 \\
Taxa de colesterol & 4 \\
Glicose sanguínea & 4 \\
Osteoporose & 3 \\
Outra & 16 \\
\hline
\end{tabular}

Fonte: Autor (2020).

\section{CONSIDERAÇÕES FINAIS}

Verificou-se com este estudo que os novos adeptos à prática de trilhas foram motivados pela vontade de estar em contato com a natureza. É interessante ressaltar que na composição do grupo há uma maior concentração de mulheres. A trilha foi representada pela natureza e o condicionamento físico.

O Rio de Janeiro é privilegiado por ser cercado por um misto de mata e mar, o que pode ter despertado a curiosidade e a aventura nos participantes, visto que o sistema intermediário teve a predominância desses termos. A representação para atividade física ficou associada à saúde e ao condicionamento físico. Foi possível observar que todos os participantes perceberam melhorias em suas vidas após dar início a esta prática, tais como: elevação de sentimentos que favorecem ao bom relacionamento interpessoal, disposição no dia a dia, humor e ânimo.

Essa representação de atividade física não foi diferente do que vem sendo difundido hegemonicamente. Mesmo que a trilha seja uma atividade que leve a pessoas a algumas reflexões sobre esse fazer, parece que essa atividade ainda não foi capaz de transcender à essa hegemonia. Esse é um tema que pode ser debatido dentro do grupo, favorecendo assim à ampliação do olhar para as possibilidades dessa prática.

\section{REFERÊNCIAS}

ANTUNES, P. de C.; SILVA, A. M.; BAPTISTA, T. J. R. Corpo e saúde na produção acadêmica da educação física brasileira: um estudo centrado na meia idade. Motrivivência, Florianópolis, ano 25, n. 41, p. 176-189, dez. 2013. Disponível em:

https://periodicos.ufsc.br/index.php/motrivivencia/article/view/2175-

8042.2013v25n41p176. Acesso em: 02 mai. 2020. 
ARMAS, C. A. de; INÁCIO, H. L de D. Seres humanos e natureza: o lazer como mediação. Licere, Belo Horizonte, v. 13, n. 2, p. 1-29, jun. 2010.

BAPTISTA, T. J. R; ZANOLLA, S. R. S. Corpo, Estética e ideologia: um diálogo com a ideia de beleza natural. Movimento, Porto Alegre, v. 22, n. 3, p. 999-1010, jul./set. 2016. Disponível em: https://www.redalyc.org/pdf/1153/115347695024.pdf. Acesso em: 24 jul. 2020.

BASTOS, L. G. V. Corpografias: entre o analógico e o digital. 2008. Tese (Doutorado em Comunicação) - Universidade Federal do Rio de Janeiro, Rio de Janeiro, 2008.

CARDOSO, F. L.; MARINHO, A.; PIMENTEL, G. G. A. Questões de gênero em universitários praticantes de esportes de aventura. Revista da Educação Física: UEM, [S. I.], v. 24, n. 4, p. 597-608, 2013.

CARDOSO, A. R.; SILVA, A.; FELIPE, G. R. A educação pela aventura: desmistificando sensações e emoções. Motriz: revista de Educação Física, Rio Claro, v. 12, n. 1, p. 77-87, 2006. Disponível em:

http://www.periodicos.rc.biblioteca.unesp.br/index.php/motriz/article/view/64/45. Acesso em: 01 mai. 2020.

DALL'OGLIO, O. T.; SHENG, L. Y.; BENITEZ, N. H. M. Perfil dos visitantes do Parque dos Buritis, município de Lucas do Rio Verde-MT. Nativa, Sinop, v. 5, n. 2, p. 107-113, mar./abr. 2017. Disponível em: http://periodicoscientificos.ufmt.br/ojs/index.php/nativa/article/view/4296. Acesso em: 01 maio 2020.

DUMAZEDIER, J. Sociologia empírica do lazer. 2. ed. São Paulo: Perspectiva: SESC, 1999.

ELIAS, N. Sobre o tempo. Rio de Janeiro: Jorge Zahar, 1998.

ESPÍRITO-SANTO, G.; MOURÃO, L. Representações de saúde, exercício físico e lazer de jovens moradores da comunidade da matriz. Revista Augustus, Rio de Janeiro, v. 17, n. 37, p. 28-57, 2012.

FERRARI, R. D. et al. Corpos, identidade e fotografia na modernidade digital. Motrivivência, Florianópolis, ano 24, n. 38, p. 262-269, jun. 2012. Disponível em: https://periodicos.ufsc.br/index.php/motrivivencia/article/view/21758042.2012v24n38p262/22979. Acesso em: 02 maio 2020.

FIGUEIREDO, J. P.; SCHWARTZ, G. M. Atividades de aventura e educação ambiental como foco nos periódicos da área de educação física. Motriz: revista de Educação Física, Rio Claro, v. 19 n. 2, p. 417-419, abr./jun. 2013. Disponível em: http://www.scielo.br/scielo.php?script=sci_arttext\&pid=S198065742013000200024\&Ing=en\&nrm=iso. Acesso em: 30 abr. 2020.

GOMES, O. C.; ISAYAMA, H. F. Corridas de aventura e lazer: um percurso analítico para além das trilhas. Motriz: revista de Educação Física, Rio Claro, v. 15, n. 1, p. 69-78, jan./mar. 2009. Disponível em: 
http://www.periodicos.rc.biblioteca.unesp.br/index.php/motriz/article/view/1472/2219. Acesso em: 01 maio 2020.

LAVOURA, T. N.; SCHWARTZ, G. M.; MACHADO, A. A. Aspectos emocionais da prática de atividades de aventura na natureza: a (re)educação dos sentidos. Revista Brasileira de Educação Física e Esporte, São Paulo, v. 22, n. 2, p. 119-127, abr./jun. 2008. Disponível em: http://www.revistas.usp.br/rbefe/article/view/16687. Acesso em: 01 maio 2020.

LUCENA, A. B.; SILVA, P. P. C.; BRASILEIRO, M. D. S. A prática do kitesurf e o universo da preservação ambiental. Licere, Belo Horizonte, v. 16, n. 1, p. 1-18, mar. 2013. Disponível em: https://periodicos.ufmg.br/index.php/licere/article/view/678. Acesso em: 12 mai. 2020.

LUIZ, F. B.; TEIXEIRA, J. C. A. Acessibilidade de idosos e as unidades de conservação: reflexões rumo à democratização dos espaços públicos de lazer. Revista Turismo: visão e ação, v. 18, n. 1, p. 164-192, jan./abr. 2016. Disponível em:

http://siaiap32.univali.br/seer/index.php/rtva/article/viewFile/8601/4830. Acesso em: 06 mai. 2020.

LUPTON, D. "Desenvolvendo-me por inteiro": cidadania, neoliberalismo e saúde contemporânea no currículo da educação física. Movimento, Porto Alegre, v. 9, n. 3, p. 1131, set./dez. 2003.

MAFFESOLI, M. No fundo das aparências. Petrópolis: Vozes, 1996.

MARINHO, A. Lazer, aventura e risco: reflexões sobre atividades realizadas na natureza. Movimento, Porto Alegre, v. 14, n. 2, p. 181-206, maio/ago. 2008. Disponível em: http://www.seer.ufrgs.br/index.php/Movimento/article/view/5756. Acesso em: 06 mai. 2020.

MATSUDO, S. M. M. Envelhecimento, atividade física e saúde. BIS: Boletim do Instituto de Saúde, São Paulo, n. 47, p. 76-19, abr. 2009. Disponível em:

http://periodicos.ses.sp.bvs.br/scielo.php?script=sci_arttext\&pid=S151818122009000200020\&lng=pt\&nrm=iso. Acesso em: 23 abr. 2020.

MOREIRA, J. C. C.; SCHWARTZ, G. M. "Caminho da fé": reflexões sobre lazer e ambiência. Motriz: revista de Educação Física, Rio Claro, v. 16, n. 3, p. 559-570, jul./set. 2010. Disponível em: http://www.scielo.br/pdf/motriz/v16n3/a03v16n3.pdf. Acesso em: 13 mai. 2020.

MOURA D. L.; SOARES A. J. G. Esporte de risco e risco no esporte: uma análise do risco no voo livre. Revista da Educação Física: UEM, [S. I.], v. 25, n. 1, p. 53-65, 2014. Disponível em: http://www.scielo.br/scielo.php?script=sci_arttext\&pid=S1983-

30832014000100053\&lng=en\&nrm=iso\&tlng=pt. Acesso em 05 mai. 2020.

PAIXÃO, J. A. et al. Risco e aventura no esporte na percepção do instrutor. Psicologia \& Sociedade, [S. I.], v. 23, n. 2, p. 415-425, 2011. Disponível em: http://www.scielo.br/pdf/psoc/v23n2/a23v23n2.pdf. Acesso em: 30 abr. 2020. 
PALMA, A. Educação Física, corpo e saúde: uma reflexão sobre outros "modos de olhar". Revista Brasileira de Ciências do Esporte, [S. I.], v. 22, n. 2, p. 23-39, jan. 2001. Disponível em: http://revista.cbce.org.br/index.php/RBCE/article/view/410/384. Acesso em: 02 maio 2020.

PALMA, A.; VILAÇA, M. M. O sedentarismo da epidemiologia. Revista brasileira de ciências do esporte, Campinas, v. 31, n. 2, p. 105-119, jan. 2010. Disponível em: https://www.redalyc.org/pdf/4013/401338541008.pdf. Acesso em: 24 jul. 2020.

PEREIRA, A. S.; PIMENTEL, G. G. A.; LARA, L. M. Atividades físicas de aventura na natureza: relações entre estilo de vida aventureiro e modo de vida rural para a melhoria da qualidade de vida. Iniciação Científica CESUMAR, v. 6, n. 2, p. 112-119, jul./dez. 2004. Disponível em: http://periodicos.unicesumar.edu.br/index.php/iccesumar/article/view/91. Acesso em: 11 maio 2020.

SÁ, C. P. de. Núcleo central das representações sociais. Petrópolis: Vozes, 2002.

SCHWARTZ, G. M. et al. Estratégia de participação da mulher nos esportes de aventura. Revista Brasileira de Ciências do Esporte, [S. I.], v. 38, n. 2, p. 156-162, 2016. Disponível em: https://www.scielo.br/pdf/rbce/v38n2/0101-3289-rbce-38-02-0156.pdf. Acesso em: 30 abr. 2020.

SECRETARIA MUNICIPAL DE MEIO AMBIENTE (Rio de Janeiro). Mapeamento da cobertura vegetal e do uso das terras do Município do Rio de Janeiro. Prefeitura da cidade do Rio de Janeiro, Rio de janeiro, 2020. Disponível em:

http://www.rio.rj.gov.br/web/smac/exibeconteudo?article-id=2367969. Acesso em: 06 maio 2020

SPINK, M. J. Psicologia social e saúde. Petrópolis: Vozes, 2003.

SPINK, M.; ARAGAKI, S. S.; ALVES, M. P. Da exacerbação dos sentidos no encontro com a natureza: contrastando esportes radicais e turismo de aventura. Psicologia: reflexão e crítica, v. 18, n. 1, p. 26-38, 2005. Disponível em:

http://www.scielo.br/pdf/prc/v18n1/24814.pdf. Acesso em: 09 maio 2020.

SZEREMETA, B.; ZANNIN, P. H. T. A importância dos parques urbanos e áreas verdes na promoção da qualidade de vida em cidade. Revista Ra'e Ga: Espaço Geográfico em Análise, Curitiba, v. 29, p. 177-193, dez. 2013. Disponível em:

http://revistas.ufpr.br/raega/article/view/30747. Acesso em: 10 maio 2020.

TAHARA, A. K.; CARNICELLI FILHO, S. Atividades físicas de aventura na natureza (AFAN) e academias de ginástica: motivos de aderência e benefícios advindos da prática. Movimento, Porto Alegre, v. 15, n. 3, p. 187-208, jul./set. 2009. Disponível em:

http://www.seer.ufrgs.br/index.php/Movimento/article/view/4917. Acesso em: 07 maio 2020.

VAZ, J. M. et al. Percepções de competências profissionais de instrutores de atividades de aventura na natureza atuantes em Florianópolis/SC. Movimento, Porto Alegre, v. 23, n. 1, p. 
TRILHAS: MOTIVAÇÕES E PERCEPÇÕES DOS

PARTICIPANTES DE UM GRUPO DO ESTADO

DO RIO DE JANEIRO
Ana Carla da Conceição Silva Nunes

Diogo Gonçalves de Souza de Oliveira Giannina Maria do Espirito Santo Wildhagen

295-310, jan./mar. 2017. Disponível em:

http://www.seer.ufrgs.br/Movimento/article/viewFile/66064/41033. Acesso em: 23 mar. 2020. 